\title{
Prevalence of Dysmenorrhea among Adolescent Girls: A Burning Issue
}

\author{
Kamal Chandrika Jampana ${ }^{1}$ \\ ${ }^{1}$ Assistant Professor, Department of Obstetrics and Gynaecology, Nimra Institute of Medical Sciences, Nimra Nagar, Ibrahimpatnam, Jupudi, Vijayawada, Andhra \\ Pradesh-521456.
}

\section{Abstract}

Background: Dysmenorrhea, defined as painful cramps that occur with menstruation, is the most common gynecologic problem in women of all ages and races and one of the most common causes of pelvic pain. Painful menses in women or dysmenorrhea is a very frequently observed gynecologic problem. The true incidence and prevalence of dysmenorrhea are not clearly established in India. Subjects and Methods: The data were collected from the schools and colleges present in Krishna district. Female medical students and a female medicosocial worker were trained for this study. Three schools and three colleges were randomly selected and from this all the girls who were willing to participate and in the age group of 14-19 years were included in the study. Results: The overall prevalence of dysmenorrhoea was $68 \%$ ( $72.3 \%$ and $63.3 \%$ in the urban and rural areas respectively). The difference in the prevalence of the urban and rural adolescent girls (study subjects) is not significant. Conclusion: Dysmenorrhoea is a very common problem. A number of physical and emotional symptoms are associated with dysmenorrhea and it also affects the quality of life of girls to a great extent.

Keywords: Menstrual characteristics, Dysmenorrhea, Prevalence \& quality of life.

Corresponding Author: Dr. Krishna Nand Prasad Gupta, Assistant Professor, Department of Orthopedics, NMCH, Jamuhar, Sasaram

Received: May 2019

Accepted: June 2019

\section{Introduction}

Exact origin of the word dysmenorrhoea is not known, but it has been mentioned in the ancient literature world-wide vivid description and social stigma associated with menstruation related mood and behavioural changes date back to Hippocrates, the Talmud and the Bible. In spite of the fact of existence of painful menstruation in ancient literature, it was only in the last half of past century when dysmenorrhea has been accorded impartial scientific evaluation. Dysmenorrhea, defined as painful cramps that occur with men-struation, is the most common gynecologic problem in women of all ages and races, ${ }^{[1]}$ and one of the most common causes of pelvic pain. ${ }^{[2]}$ Dysmenorrhea may be categorized into two distinct types: primary and secondary. Primary dysmenorrhea is defined as painful menses in women with normal pelvic anatomy, usually beginning during adolescence. ${ }^{[3]}$ Secondary dysmenorrhea is menstrual pain associated with underlying pathology, and its onset may be years after menarche. There is a wide variation in the estimate of dysmenorrhea from studies around the world reporting a range between $28 \%$ and $71.7 \% .^{[4,5]}$ Various studies in India revealed that the prevalence of dysmenorrhea varies from $33 \%$ to $79.67 \%$. $^{[6-}$ 10] However, the true incidence and prevalence of dysmenorrhea are not clearly established in India. According to studies dysmenorrhea is interrupting their educational and social life. ${ }^{[11]}$ Due to dysmenorrhea sickness absenteeism (28- 48\%) and perceived quality of life losses are prevalent among adolescent girls. ${ }^{[6-9]}$ In the
United States dysmenorrhea has been estimated to be the greatest cause of time lost from work and school. ${ }^{[12]}$ Aim of this present study was to evaluate the prevalence of dysmenorrhea and its common symptoms as well as to determine the sickness absenteeism due to dysmenorrhea and to asses the quality of life among the dysmenorrhic girls.

\section{Subjects and Methods}

This study was conducted in the Department of Obstetrics and Gynaecology, Nimra Institute of Medical Sciences, during the period of sixteen months i.e., from September 2016 to December 2017. The data were collected from the schools and colleges present in Krishna district. Female medical students and a female medico-social workers were trained for this study. Three schools and three colleges randomly selected and from this all the girls who were willing to participate and in the age group of 14-19 years were included in the study. The total sample size was 125 . The tool developed was a pretested semistructured questionnaire. The items included were age at menarche, presence and absence of dysmenorrhea, its duration, amount of blood loss, irregularity and symptoms experienced during menstruation, family history, sickness absenteeism \& quality of life related questions.

The following criteria were used to define dysmenorrhoea: ${ }^{[13]}$

- Onset of pain within 6-12 hours after menarche. 
- Lower abdominal or pelvic pain associated with onset of menses and lasting for 8-72 hours.

- Lower back pain during menses.

- Medial or anterior thigh pain.

The survey was completed and data was analyzed for the results with percentages.

The collected data was analyzed using descriptive and inferential statistics.

\section{Results \& Discussion}

The average age of the participants was found to be between 14-16 years. Around $60.8 \%$ (76) were in the age range of 14 to 16 years and $37.6 \%$ (47) were between 1619 years. Majority of the participants $(78.4 \%)$ had a normal BMI (18-23 kg/m2), whereas underweight and overweight categories had almost equal distribution with $10.4 \%$ and $11.2 \%$, respectively[Table 1$]$.

Table 1:Frequency and percentage distribution of sample characteristics, $\mathbf{N}=125$.

\begin{tabular}{|l|l|l|}
\hline Sr. no. & Characteristics & Frequency (\%) \\
\hline \multicolumn{2}{|l|}{ Age in years } & \multicolumn{1}{|c|}{} \\
\hline 1. & $<13-16$ & $2(1.6 \%)$ \\
\hline 2. & $16-19$ & $76(60.8 \%)$ \\
\hline 3. & $>19$ & $47(37.6 \%)$ \\
\hline 4. & Under-weight & \\
\hline Body Mass Index & $13(10.4 \%)$ \\
\hline 1. & Normal & $98(78.4 \%)$ \\
\hline 2. & Over-weight & $14(11.2 \%)$ \\
\hline 3. &
\end{tabular}

The overall prevalence of dysmenorrhoea was $68 \%(72.3 \%$ and $63.3 \%$ in the urban and rural areas respectively). The difference in the prevalence of the urban and rural adolescent girls (study subjects) is not significant. ( $\chi 2=1.2$, $\mathrm{P}>0.05)$ [Table 2].

Table 2: Prevalence of dysmenorrhea in adolescent girls.

\begin{tabular}{|l|l|l|l|}
\hline Dysmenorrhea & Urban (\%) & Rural (\%) & Total (\%) \\
\hline Present & $47(72.3 \%)$ & $38(63.3 \%)$ & $85(68 \%)$ \\
\hline Absent & $18(27.7 \%)$ & $22(36.7 \%)$ & $40(32 \%)$ \\
\hline Total & $65(100 \%)$ & $60(100 \%)$ & $125(100 \%)$ \\
\hline
\end{tabular}

Findings of [Table $1 \& 2$ ] suggests that participants in the study with the history of early age at menarche had more prevalence of dysmenorrhea but it is statistically not significant. Among dysmenorrhic girls associated symptoms are headache, Vomiting \&Diarrhoea (16.4\%, $10.6 \% \& 7.3 \%$ ) respectively. Prevalence of dysmenorrhea was significantly more among the girls with family history of dysmenorrhea.[Table 3]

Table 3: Family history of dysmenorrhea and prevalence of dysmenorrhea

\begin{tabular}{|l|l|l|l|}
\hline $\begin{array}{l}\text { History of } \\
\text { Family }\end{array}$ & $\begin{array}{l}\text { Dysmenorrhic } \\
(\boldsymbol{\%})\end{array}$ & $\begin{array}{l}\text { Non- } \\
\text { Dysmenorrhic(\%) }\end{array}$ & Total (\%) \\
\hline Present & $41(75.9 \%)$ & $13(24.1 \%)$ & $54(100 \%)$ \\
\hline Not present & $43(60.6 \%)$ & $28(39.4 \%)$ & $71(100 \%)$ \\
\hline
\end{tabular}

Majority of the dysmenorrhic girls are experiencing disgusted $(80.4 \%)$, irritability $(69.5 \%)$, emotional instability $(43.2 \%)$, loss of interest in regular work $(62.5 \%)$, disturbed sleep $(54.7 \%) \&$ reduced appetite $(51.6 \%)$ during menstrual period, these experiences are significantly less in non dysmenorrhic girls. [Table 4] clearly shows that Sickness absenteeism is significantly more among dysmenorrhic girls than non dysmenorrhic girls during menstrual period. Table 5 shows the $21.28 \%, 62.77 \%$ and $15.96 \%$ of girls had mild, moderate and severe pain, respectively.

Table 4: Sickness absenteeism among dysmennorhic and non dysmennorhic girls

\begin{tabular}{|l|l|l|}
\hline $\begin{array}{l}\text { Sickness } \\
\text { absenteeism }\end{array}$ & Dysmenorrhic (\%) & $\begin{array}{l}\text { Non-Dysmenorrhic } \\
(\boldsymbol{\%})\end{array}$ \\
\hline Present & $38(46.9 \%)$ & $9(20.4 \%)$ \\
\hline Absent & $43(53.1 \%)$ & $35(79.5 \%)$ \\
\hline Total & $81(100 \%)$ & $44(100 \%)$ \\
\hline \multicolumn{2}{|l|}{ (Statistically Significant at p value $<0.05 ;$ *NS: Statistically not significant) }
\end{tabular}

Table 5: Frequency and percentage distribution of Pain characteristics of girls with Dysmenorrhea, $N=85$

\begin{tabular}{|c|c|c|}
\hline Sr. no. & Menstrual characteristics & Frequency (\%) \\
\hline \multicolumn{3}{|c|}{ A. Onset of Pain } \\
\hline 1. & Before menses & $19(22.3 \%)$ \\
\hline 2. & Day 1 of Menses & $47(55.3 \%)$ \\
\hline 3. & Day 2 or 3 of Menses & $21(24.7 \%)$ \\
\hline \multicolumn{3}{|c|}{ B. No. of Pain days } \\
\hline 1. & 1 day & $28(32.9 \%)$ \\
\hline 2. & 2 days & $36(42.3 \%)$ \\
\hline 3. & 3 days & $16(18.8 \%)$ \\
\hline 4. & More than or equal to 4 days & $3(3.5 \%)$ \\
\hline \multicolumn{3}{|c|}{ C. Severity of Pain } \\
\hline 1. & Severe $(7-10)$ & $13(15.3 \%)$ \\
\hline 2. & Moderate (4-7) & $53(62.3 \%)$ \\
\hline 3. & Mild (2-4) & $18(21.2 \%)$ \\
\hline
\end{tabular}

Table 6: Quality of life loss among dysmenorrhic and non dysmenorrhic girls

\begin{tabular}{|l|l|l|}
\hline $\begin{array}{l}\text { Quality of life } \\
\text { characteristics }\end{array}$ & $\begin{array}{l}\text { Dysmenorrhic } \\
\mathbf{n = ~ 8 1}(\boldsymbol{\%})\end{array}$ & $\begin{array}{l}\text { Non Dysmenorrhic } \\
\mathbf{n = 4 4}(\mathbf{\%})\end{array}$ \\
\hline $\begin{array}{l}\text { Reduced Levels of } \\
\text { confidence at work }\end{array}$ & $43(53.1)$ & $15(34.1)$ \\
\hline $\begin{array}{l}\text { Poor Work } \\
\text { satisfaction }\end{array}$ & $14(17.3)$ & $3(4.5)$ \\
\hline $\begin{array}{l}\text { Loss of Concentration } \\
\text { level }\end{array}$ & $48(59.2)$ & $12(27.3)$ \\
\hline $\begin{array}{l}\text { Poor personal } \\
\text { relationships }\end{array}$ & $43(53.1)$ & $10(22.7)$ \\
\hline $\begin{array}{l}\text { Decreased physical } \\
\text { activity }\end{array}$ & $20(24.7)$ & $2(2.3)$ \\
\hline
\end{tabular}

[Table 5] shows that quality of life is significantly affected among dysmenorrhic girls. For the management of dysmenorrhea $71.5 \%$ of rural girls are relying on self-help technique as compared to $54.3 \%$ of urban girls and only $25.8 \%$ of rural girls are using medication as compared to $43.4 \%$ of the urban girls which is statistically significant.

The findings of this present study showed a high prevalence of dysmenorrhea, that is, $68 \%$ among adolescent girls of Krishna district, Similar findings were reported by Sharma P, Malhotra C, Taneja DK etal (67.2\%), ${ }^{[9]}$ Sharma M and Gupta S. (67\%), ${ }^{[14]}$ Mckay and Diem (67\%), ${ }^{[15]}$ Sundell G, 
Milsom I, Andersch B. (67\%), ${ }^{[16]}$ Jayashree R, Jayalakshmi VY. $(74 \%){ }^{[17]}$ and Harlow and Park (71.6\%). ${ }^{[18]}$ Comparatively lower prevalence had been reported by Sharma A, Taneja DK, Sharma P, et al $(33 \%),{ }^{[6]} \mathrm{Nag}$ $(33.84 \%),{ }^{[19]}$ Singh MM, Devi R, Gupta SS. (40.7), ${ }^{[7]}$ Dysmenorrhea seems to be Familial problem similar conclusion made by Avasarala AK and Panchangam S.in their study ${ }^{[8]}$ In this study, it was revealed that $21.2 \%, 62.3$ $7 \%$ and $15.3 \%$ of girls had mild, moderate and severe pain, respectively. In a study conducted by Ortiz in 1539 students of Mexican University, author concluded that dysmenorrhea was mild in $36.1 \%$, moderate in $43.8 \%$ and severe in $20.1 \% .{ }^{[20]}$ Maitri shah et al., have found that $18 \%, 40 \%$ and $42 \%$ of students had mild, moderate and severe pain (dysmenorrhea), respectively. ${ }^{[21]}$ Sickness absenteeism is significantly more among dysmenorrhic girls similar finding observed by Avasarala $\mathrm{AK}$ and Panchangam S..$^{[8]}$ and Weissmen AM, Hartz AJ, Hansen MD, et al. ${ }^{[22]}$ Sickness absenteeism because of dysmenorrhoea causes wastage of millions of dollars in the U.S.A. as per the Bergsjo's study. ${ }^{[23]}$ The quality-of-life during dysmenorrhoea is comparatively poor among dysmenorrhic girls; loss of physical activity and work satisfaction, personal relationships, confidence \& concentration at work also suffers. This clearly indicates that dysmenorrhoea is disturbing their life more when compared with the lives of the non dysmenorrhic girls. The restricted activity, regular work and relationship seen in this study is also found by Avasarala AK and Panchangam S. ${ }^{[8]}$ and Adeyemi AS and Adekanle DA. ${ }^{[13]}$ The girls in urban areas cannot cope up dysmenorrhoea and they have resorted to medication as also shown by El-Gilany AH, Badawi K, El-Fedawy S. ${ }^{[24]}$ and Awasarala AK and Panchangam S. ${ }^{[8]}$ On the contrary, the girls in the rural areas are adapting to the situation by endurance and managing the problem without drugs to a large extent. They are using self-help techniques such as cold baths, lying supine, hot fomentation, home remedies like eating Fenugreek etc. There is limited and inconsistent evidence on the effectiveness of nonpharmacologic therapies for primary dysmenorrhea. ${ }^{[25]}$ Expert consensus, ${ }^{[26-28]}$ and a small study suggest that topical heat may be as effective as NSAIDs, but there is insufficient evidence for acupuncture, yoga, and massage. ${ }^{[29]}$ Exercise, ${ }^{[30,27,32]}$ and nutritional interventions (supplementation or increased intake of omega-3 fatty acids and vitamin B) may provide some benefit, ${ }^{[26-28]}$ but the evidence is limited to small RCTs. ${ }^{[28]}$

\section{Conclusion}

These findings suggest that the dysmenorrhoea is a very common problem number of physical and emotional symptoms associated with dysmenorrhea and it also affects their quality of life of girls to a great extent. It can be better managed by mental preparation and by appropriate change in lifestyle like regular physical exercise. The urban girls should be reassured that their problem is likely to be short lived and can be managed by some self-help techniques, indulging in work rather than seeking drugs. The magnitude and intensity of problem demands appropriate intervention through education and change in lifestyle.

\section{References}

1. Proctor M, Farquhar C. Diagnosis and management of dysmenorrhoea. BMJ. 2006;332(7550):1134-1138.

2. Nasir L, Bope ET. Management of pelvic pain from dys $\neg$ menorrhea or endometriosis. J Am Board FamPract. 2004;17(suppl):S43-S47.

3. Avasarala AK, Panchangam S. Dysmenorrhoea in different settings: Are the rural and urban adolescent girls perceiving and managing the dysmenorrhoea problem differently? Indian $\mathrm{J}$ Community Med.2008;33:246-9.

4. Burnett MA, Antao V, Black A, Feldman K, Grenville A, Lea R, et al. Prevalence of primary dysmenorrhea in Canada. J ObstetGynaecol Can. 2005;27:765- 70.

5. Pitts MK, Ferris JA, Smith AM, Shelley JM, Richters J. Prevalence and correlates of three types of pelvic pain in a nationally representative sample of Australian women. Med J Aust. 2008; 189:138-43.

6. Sharma A, Taneja DK, Sharma P, Saha R. Problems related to menstruation and their effect on daily routine of students of a medical college in Delhi, India. Asia Pac J Public Health. 2008;20(3):234-41. Epub 2008 May 28.

7. Singh MM, Devi R, Gupta SS. Awareness and health seeking behaviour of rural adolescent school girls on menstrual and reproductive health problems. Indian J Med Sci. 1999 Oct;53(10):43943.

8. Avasarala AK, Panchangam S. Dysmenorrhoea in different settings: are the rural and urban adolescent girls perceiving and managing the dysmenorrhoea problem differently? Indian J Community Med. 2008 Oct;33(4):246-9.

9. Sharma P, Malhotra C, Taneja DK, Saha R. Problems related to menstruation amongst adolescent girls. Indian J Pediatr. 2008 Feb;75(2):125-9.

10. Agarwal AK, Agarwal A. A study of dysmenorrhea during menstruation in adolescent girls. Indian J Community Med. 2010 Jan;35(1):159-64.

11. Dawn CS. Textbook of Gynaecology and Contraception. 10th ed. Calcutta: Dawn Books; 1990.

12. Waite LJ. US women at work. Population Bull. 1981;36:3.

13. Adeyemi AS, Adekanle DA. Management of dysmenorrhoea among medical students. Int J Gynecol Obstet. 2007;7:1528-39.

14. Sharma M, Gupta S. Menstrual pattern and abnormalities in the high school girls of Dharan: a cross sectional study in two boarding schools. Nepal Med Coll J. 2003 Jun;5(1):34-6.

15. McKay L, Diem E. Concerns of adolescent girls. J PediatrNurs. 1995;10:19-27.

16. Sundell G, Milsom I, Andersch B. Factors influencing the prevalence and severity of dysmenorrhea in young women. Br J ObstetGynaecol. 1990;97:588-94.

17. Jayashree R, Jayalakshmi VY. Socio-cultural dimensions of menstrual problems. Health Educ South East Asia. 1997;12:21-6.

18. Harlow SD, Park M. A longitudinal study of risk factors for the occurrence, duration and severity of menstrual cramps in a cohort of college women. Br J ObstetGynaecol. 1996;103:1134-42.

19. Nag RM. Adolescent in India. Calcutta: Medical Allied Agency; 1982. pp. 18-26.

20. Ortiz MI. Primary dysmenorrhea among Mexican university students: Prevalence, impact and treatment.Eur J ObstetGynecolReprod Biol. 2010;152:73-7.

21. Shah M, Monga A, Patel S, Shah M, Bakshi H. A study of prevalence of primary dysmenorrhea in young students-A cross-sectional study. Healthline. 2013;4:30-4.

22. Weissmen AM, Hartz AJ, Hansen MD, Johnson SR. The natural history of primary dysmenorrhoea: A longitudinal study. BJOG. 2004;111:345-52.

23. Bergsjo P. Socioeconomic implications of dysmenorrhoea. ActaObstetGynecol Scand.1979;87:67.

24. El-Gilany AH, Badawi K, El-Fedawy S. Epidemiology of dysmenorrhoea among adolescent students in Mansoura, Egypt. East 
Meditarr Health J. 2005;11:155-63.

25. Proctor ML, Murphy PA, Pattison HM, Suckling J, Farqu $\neg$ har CM. Behavioural interventions for primary and sec $\neg$ ondarydysmenorrhoea. Cochrane Database Syst Rev. 2007;(3):CD002248.

26. Harel Z. Dysmenorrhea in adolescents and young adults: etiology and management. J PediatrAdolesc Gynecol. 2006;19(6):363-371.

27. French L. Dysmenorrhea. Am Fam Physician. 2005;71(2): 285-291.

28. Morrow C, Naumburg EH. Dysmenorrhea. Prim Care. 2009;36(1):1932.

29. Akin MD, Weingand KW, Hengehold DA, Goodale MB, Hinkle RT,
Smith RP. Continuous low-level topical heat in the treatment of dysmenorrhea. Obstet Gynecol. 2001;97(3):343-349.

30. Marjoribanks J, Proctor M, Farquhar C, Derks RS. Non $\neg$ steroidal antiinflammatory drugs for dysmenorrhoea. Cochrane Database Syst Rev. 2010;(1):CD001751.

31. Brown J, Brown S. Exercise for dysmenorrhoea. Cochrane Database Syst Rev. 2010;(2):CD004142.

Copyright: (C) the author(s), 2019. It is an open-access article distributed under the terms of the Creative Commons Attribution License (CC BY 4.0), which permits authors to retain ownership of the copyright for their content, and allow anyone to download, reuse, reprint, modify, distribute and/or copy the content as long as the original authors and source are cited.

How to cite this article: Jampana KC. Prevalence of Dysmenorrhea among Adolescent Girls: A Burning Issue.Asian J. Med. Res. 2019;8(2):OG04-OG07.

DOI: dx.doi.org/10.21276/ajmr.2019.8.2.OG2 